\title{
The perfect fit? Balancing predictive power and computational complexity for an atomistic model as prerequisite for nano-scale simulations
} A Maaß*1, TJ Müller², L Nikitina ${ }^{1}$ and M Hülsmann ${ }^{1}$

Address: ${ }^{1}$ Fraunhofer Institute SCAI, Schloss Birlinghoven, 53754 Sankt Augustin, Germany and 2Darmstadt, Germany

* Corresponding author

from 4th German Conference on Chemoinformatics

Goslar, Germany. 9-II November 2008

Published: 5 June 2009

Chemistry Central Journal 2009, 3(Suppl I):OI4 doi:I0.II86/I752-I53X-3-SI-OI4

This abstract is available from: http://www.journal.chemistrycentral.com/content/3/SI/OI4

(C) 2009 Maaß et al; licensee BioMed Central Ltd.

When aiming at quantitative predictions for materials that require huge system sizes in simulation - such as polymers - models at coarse-grained level are the natural choice. However, capturing the chemical identity of beads that are void of any individual structure resembling the original compound is a critical point for achieving meaningful predictions. As the coarse grained model inherits the features from an atomistic precursor, the latter needs to be most predictive. This may be achieved by calibrating the detailed model carefully to experimental data, thereby enhancing the atomistic model structure with most realistic behaviour [1].

Diverse strategies like e.g. simplex optimization [2][3], interactive design parameter optimization [4][5], i.e. local optimization versus global search, have been applied to study the polymer precursor ethylene-epoxide and have been intensively investigated in order to identify a viable route to a perfectly tailored atomistic model. Obviously, each strategy has its profits and limitations, the bottomline being that a final model needs to yield results that are not only accurate, but also to be robust with respect to transfer between independent program packages. For ethylene-oxide several competing models have been published $[1,6][7][8][9][10]$, however not all are suited for a later coarse graining step. The present field report details newly created models, as well as the tested methods, thus it documents the progress with respect to the long term objective of accurate property predictions for nano-scale simulations.

\section{References}

I. Müller TJ, Roy S, Zhao W, Maaß A, Reith D: Fluid Phase Equilib 2008 in press.

2. Faller R, Schmitz H, Biermann O, Müller-Plathe F: J Comp Chem I999, 20(10): 1009 .

3. Müller-Plathe F: Comput Phys Commun 1993, 78:77.

4. Thole CA, Nikitina L, Nikitin I, Steffes-lai D, Roel K, Bruns J: Fraunhofer Publica 2007.

5. Steffes-IAi D, Thole CA, Nikitin I, Nikitina L: ERCIM News 2008, 73:29.

6. Wielopolski PA, Smith ER: Mol Physics 1985, 54(2):467.

7. Mountain RD: J Phys Chem B 2005, 109:13352.

8. Li X, Zhao L, Cheng T, Liu L, Sun H: Fluid Phase Equilib 2008 in press.

9. Olson JD, Wilson LC: Fluid Phase Equilibria 2008 in press.

10. Eckl B, Vrabec J, Hasse H: Fluid Phase Equilibria 2008 in press. 